\section{La vigencia de Sor Juana Inés de la Cruz}

\author{
Herón Pérez Martínez*
}

\section{RESUMEN}

A más de trescientos doce años de la muerte de Sor Juana Inés de la Cruz, no sólo aún no tenemos una biografía fidedigna de la poetisa sino que tampoco tenemos un estudio completo de su obra poética que, como hoy se sabe, se fue tejiendo al calor de las circunstancias de su vida. Impedimento para lo primero son los aún no totalmente despejados "puntos oscuros" y los aún no resueltos "misterios" que, en expresión de algunos estudiosos, la han circundado. Y sin embargo, el caudal de publicaciones que durante el siglo XX y lo que va del presente nos presentan una Sor Juana viva y presente en la vida académica hispánica

\section{PALABRAS CLAVE}

Biografía, Poética, Textos sorjuanianos, Trampas de la fe, Humanismo, Obra literaria, Crítica literaria.

* Tiene un Doctorado en Letras con especialidad en lenguas románicas, por la Universidad de Bourgogne, Francia. Ha sido miembro de la Academia Mexicana de Ciencias y de la Lengua. Profesor Catedrático del Colegio de Michoacán, México.

Rec. 28-02-07 Acep. 18-10-07

\section{ABSTRACT}

After more than three hundred and twelve years from the death of Sor Juana Inés de la Cruz, we are still lacking a reliable biography of the poet and an exhaustive study of her poetic work, which, as we know, was weaved throughout the heated circumstances of her life. The still unclear "dark points" and the unsolved "mysteries" that, according to some scholars, encircles her life are the major impediments for her biography to be completed. However, the number of publications that since the $20^{\text {th }}$ Century and up to this moment has been printed shows a living Sor Juana present in the Hispanic academic life.

\section{KEYWORDS}

Biography, Poetic, Sor Juana texts, Tramps of faith, Humanism, Literary work, Literary Criticism

\section{Sor Juana, los Episodios de una recuperación}

Para una biografía fidedigna de Sor Juana todavía hay viejos cliché circulando, datos falsos, puntos oscuros manejados como "misterios" $\mathrm{y}$, en general, carencia de datos sobre una buena cantidad de aspectos de su vida. A obstaculizar la presentación de una poética completa de la obra sorjuaniana, concurre la falta de un estudio sistemático de toda la obra literaria de la monja novohispana, si bien hoy disponemos de un respetable corpus de estudios hechos con una herramienta teórica de primera, con rigor y paciencia. La empresa, 


\section{ESPIGA}

pues, de esbozar, una poética biográfica de la Décima Musa se basa en un respetable rescate tanto de los textos sorjuanianos como de los estudios dedicados a la poetisa.

La ilusión de escribir una biografía de Sor Juana Inés de la Cruz o de contribuir con algo a ella formó parte de los proyectos de muchos e importantes escritores del siglo XX, tanto en México como en otras partes. Se puede dividir la investigación sorjuanista del siglo XX en dos grandes épocas: la época premendezplancartiana, que va de principios del siglo XX a la publicación, culminada en 1957, de las Obras Completas, ${ }^{1}$ dos años después de la muerte de su autor, el humanista zamorano Alfonso Méndez Plancarte. En el sorjuanismo de esta primera época predomina el diletantismo. Se la puede identificar, si se prefiere, con la prehistoria del sorjuanismo académico que empezó a cundir a partir de allí cuyos hitos más importantes serán señalados más adelante. De allí arranca la segunda época, la época postmendezplancartiana. Va de 1957 al tercer centenario de la muerte de Sor Juana en 1995 que produjo una magna erupción de fie-

1. Me refiero, obviamente a Sor Juana Inés de la Cruz, Obras completas, cuatro tomos, Edición, prólogo y notas de Alfonso Méndez Plancarte, México, FCE, 19511957. De esta edición véase más adelante lo relativo al cuarto tomo. bre sorjuanista que inundó el escenario con abundantes publicaciones y marcarían el punto de arranque de una tercera época del sorjuanismo: la época actual. 2

La segunda de estas épocas se caracteriza por el trabajo pionero y paciente, y también de muchos logros. Sin embargo, en ella no han faltado textos por aquí y por allá, genuinos, como la carta de Sor Juana a su confesor, descubierta en Monterrey por el acucioso sorjuanista Aureliano Tapia Méndez en 19793 o como algunos sonetos y alguna que otra composición. Estos hallazgos aún no invalidan la edición del humanista zamorano. Pero aún frente al eventual horizonte de una nueva edición, crítica o no, la edición méndezplancartiana sigue siendo un punto de referencia obligado. Además, después de esa edición no han faltado hallazgos de textos no sorjuanianos que en el transcurso de la discusión suscitada en torno suyo han dado pie a una reflexión más madura sobre los

2. De hecho, la publicación de las Obras completas de Sor Juana concluida en 1957marca el inicio de la verdadera investigación sorjuanista. Los hitos que en ella se pueden distinguir, y de los que hablaremos más adelante, se refieren a este sorjuanismo académico.

3. Véanse nuestros Estudios Sorjuanianos, Morelia, Instituto Michoacano de Cultura, 1988. 
datos disponibles. Hoy el horizonte parece, en todo caso, más despejado.

Sin embargo, si bien llena de investigación y de hallazgos, desde el punto de vista de ciertos paradigmas de lo biográfico, la época anterior a 1957 pertenece aún, como decíamos, a la prehistoria del sorjuanismo: es época en que dominan aún las medias verdades y en donde la investigación sorjuanista en torno a la biografía de la monja depende en gran medida de los datos semihagiográficos aportados por el jesuita Diego Calleja en su célebre "aprobación" a Fama y obras póstumas de 1700. El cúmulo de biografías que de la monja se escriben en esta primera época tiene, en efecto, aún el sabor panegírico del texto de Calleja y un marcado sabor hagiográfico. A la zaga de Amado Nervo, hubo en la primera mitad del siglo XX una gran cantidad de escritores de la talla de Alfonso Reyes, Pedro Henríquez Ureña, Genaro Estrada, Ezequiel A. Chávez, Genaro Fernández McGregor, Karl Vossler, Alfonso Junco, Gabriela Mistral, Enrique Díez-Canedo, Concha de Salamanca, Dorothy Schons, Manuel Toussaint, Julio Jiménez Rueda, Xavier Villaurrutia, Ludwig Pfandl, Rubén Salazar Mallén, Jorge Cuesta, Ermilo Abreu Gómez o Anita Arroyo que, en los vastos dominios de la investigación literaria e his- toriográfica, a secas, se dedicaron a juntar granitos de arena, quien más quien menos, para ir construyendo con paciencia una morada biográfica para Sor Juana Inés de la Cruz. En este lapso tuvieron lugar investigaciones brillantes: se puede decir que esta primera mitad del siglo XX determina, en otro sentido, los comienzos de la investigación rigurosa sobre Sor Juana Inés de la Cruz cuya expresión más a la mano es la referida edición de las Obras completas de la poetisa novohispana: el motor de estos trabajos es la gran fascinación que la poetisa provoca. Si bien la referida biografía hagiográfica de Calleja fue y sigue siendo un punto de referencia obligado, no faltaron ya quienes empezaron a transitar por rutas propias.

En todo caso, la investigación sorjuanista en esta primera parte del siglo XX está condicionada por el gran vacío existente entonces de unas Obras Completas de Sor Juana. En efecto, fuera de los tres tomos que de la obra sorjuaniana se habían publicado entre 1689 y 1700, el resto de sus escritos vagaba de una colección a otra, en bibliografías o en tímidas ediciones casi caseras. Así, son pioneros en la investigación bibliográfica sorjuaniana tanto Pedro Henríquez Ureña con su Bibliografía de Sor Juana aparecida en París en 
1917, como Dorothy Schons 4 y Ermilo Abreu Gómez, este último con su discutida Bibliografía y biblioteca de Sor Juana Inés de la Cruz que motivó y mereció la serie de artículos de Alfonso Méndez Plancarte en El Universal desde octubre de 1943 hasta $1955.5^{5} \mathrm{Y}$ aún don Emeterio Valverde Téllez, el sabio obispo de León, quien en su Biblografía filosófica mexicana, 6 no sólo incluye una serie de rasgos biográficos de la poetisa, sino que reproduce la minibiografía del retrato que de Sor Juana hay en el Museo Provincial de Toledo, resumen de la de Calleja, además de una relativamente vasta bibliografía de la monja y acerca de ésta.

A Henríquez Ureña y a Dorothy Schons, por lo demás, se deben los inicios de la investigación propiamente científica en torno a obra y vida de Sor Juana. Son paradigmáti-

4. Bibliografía de Sor Juana, 1925 y 1927.

5. Lo más significativo de la polémica Méndez Plancarte-Abreu apareció en El Universal, artículos del 11, 18 y 25 de sept. y del 2 y 9 de oct. de 1944; y sobre el "Prólogo" a las Poesías Selectas, 1940, véase El Universal, los días 7, 14, 21 y 28 de mayo, y 4 y 11 de junio de 1945. A ello se refiere con detalle Tarsicio Herrera Z. en su Buena fe y humanismo en Sor Juana, México, Porrúa, 1984, pp. 9 y ss.

6. Estudio introductorio por Herón Pérez Martínez, índices preparados por Pilar González y Marcelo Sada, edición facsimilar, Zamora, El Colegio de Michoacán, 1989, pp. 32-52. cas de esta primera época las mencionadas discusiones entre Alfonso Méndez Plancarte y Ermilo Abreu Gómez sobre la biblioteca de Sor Juana. Parte de esta polémica sería recogida en 1982 por don Octaviano Valdés en un librito titulado Crítica de críticas. ${ }^{7}$ También Octavio Paz da cuenta de ella tachando los artículos mendezplancartianos de $\mathrm{El}$ Universal de críticas severas, feroces y arrogantes en su Sor Juana Inés de la Cruz o las trampas de la fe. ${ }^{8}$ Por otro lado, hasta las investigaciones de Guillermo Ramírez España, publicadas por la Imprenta Universitaria en 1947 se seguía ignorando lo que Anita Arroyo llamaría más tarde "el enigma del origen". Entre los ensayos, de una u otra manera biográficos, que actualmente cabría destacar, está la Sor Juana Inés de la Cruz. La décima musa de México, del alemán Ludwig Pfandl que, traducida al español, fue editada por don Francisco de la Maza. ${ }^{9}$ Para llevar a cabo su intento de psicoanálisis de Sor Juana, Pfandl se basa en los datos biográficos de que disponía en 1945. Como, muy bien señala de la Maza, de haberla conocido, Pfandl hubiera sacado mucho jugo

7. México, Ediciones Las Hojas del mate, Protasio Tagle 61, Tacubaya, D. F., 1982.

8. Tercera edición, México, FCE, 1983, pp. 92, 324 y 325.

9. México, UNAM, 1983. 
"de la ilegitimidad del nacimiento de Juana Inés" ${ }^{10}$ Un intento más reciente de psicoanalizar a la monja novohispana, llevado a cabo por Fredo Arias de la Canal en su libro Intento de psicoanálisis de Juana Inés y otros ensayos sorjuanistas, 11 se basa en un documentado análisis, desde esa perspectiva, de la obra de Sor Juana más que de su vida.

Tanto por la información que maneja como por la influencia que ha ejercido gracias a la poderosa red de publicidad de que ha gozado, hay que señalar el lugar destacado que ocupa la citada obra de Octavio Paz, Sor Juana Inés de la Cruz o las trampas de la fe. Sin embargo, aunque con menos aparato publicitario, otras obras tanto o más importantes han aparecido en estas cuatro décadas. En ese sentido, hay que mencionar una investigación ejemplar que ordena los datos hasta entonces disponibles sobre la vida de Sor Juana y los hace avanzar en varios puntos: me refiero a la investigación que realiza la profesora francesa MariéCécile Benassy-Berling en una tesis doctoral sustentada el 5 de junio de 1979 en la Sorbonne Nouvelle y publicada en español cuatro años después bajo el título de Humanismo y religión en Sor Juana Inés de la

10. Op.cit., p. XIV.

11. México, Frente de Afirmación Hispanista, 1988.
$\mathrm{Cruz}^{12}$ en que se echa a cuestas la tarea de describir la"religión personal de Sor Juana, sin pretender dar todas las claves de acceso a ella". 13 De ese mismo alcance es la obra de don Francisco de la Maza, Sor Juana Inés de la Cruz ante la historia, 14 en que recoge, como lo dice el mismo subtítulo, Biografías antiguas. La fama de 1700. Noticias de 1667 a 1892. Muchas otras han sido las contribuciones que antes y después de las Obras Completas han contribuido a esclarecer la vida y obra de Sor Juana. Como un ejemplo de lo que se sabe y se dice actualmente sobre Sor Juana puede servir el libro recientemente publicado por Sara Poot Herrera (editora), $Y$ diversa de mí misma entre plumas ando. Homenaje internacional a Sor Juana Inés de la Cruz. ${ }^{15}$

\section{Alfonso Méndez Plancarte y las Obras completas}

La edición de las Obras completas de Sor Juana Inés de la Cruz, aparecidas entre 1951 y 1957 por obra del humanista zamorano Alfonso Méndez Plancarte, los tres primeros

12. México, UNAM, 1983.

13. Op. cit., p. 398.

14. Publicado bajo el cuidado y revisión de Elías Trabulse, México, UNAM, 1980.

15. México, El Colegio de México, 1993. 


\section{ESPIGA}

tomos, y de Alberto G. Salceda, el cuarto, constituye el más importante acontecimiento para el sorjuanismo durante el siglo XX. Este suceso se preparó desde la primera mitad del siglo XX tomando como punto de referencia la supuesta fecha de nacimiento de la poetisa. La fecha que por entonces se tenía como verdadera, el 12 de noviembre de 1951, es hoy considerada errónea. Hoy se piensa que Sor Juana Inés de la Cruz nació los mismos días y mes de 1648. Como resultado de la euforia sorjuanista del momento y del orden establecido por los editores de las Obras completas hubo un alud de documentos que vinieron a perfeccionar el cuadro que hasta entonces se basaba en el primer esquemita biográfico, el del jesuita Diego Calleja, correspondiente contemporáneo y primer biógrafo de la "décima musa"...

El editor de los tres primeros tomos de las Obras Completas de Sor Juana puede ser considerado, por muchas razones, como una cumbre en la investigación sorjuanista y sigue siendo, por esta razón, un punto de referencia obligado. Bien puede el investigador servirse de él, por tanto, si quiere hacer un somero inventario de lo que hasta ahora se sabe y se dice de la vida de Sor Juana. En efecto, salvo las coloraciones hagiográficas que la matizan estilísticamente, aún puede servir de orientación la biografía que Alfonso Méndez Plancarte publica en Abside en 1951 bajo el nombre de "Tríptico de la Fénix" con ocasión del tercer centenario tradicional del nacimiento de la monja el 12 de noviembre de ese año. Allí reproduce el sabio sorjuanista, ampliándola, la biografía que de la poetisa aparece en su "Introducción" al primer tomo de las Obras Completas bajo el título de "La vida, la obra y la perenidad de Sor Juana Inés de la Cruz" expuesta, como él dice, "en ceñida síntesis". 16

El primer punto sobre el que hay que llamar la atención es la cuestión de la tradicional fecha de nacimiento de Sor Juana que Méndez Plancarte no sólo pone en duda sino que, a la zaga de las importantes investigaciones que Guillermo Ramírez España realiza sobre la familia de Sor Juana, reproduce las razones y la documentación que la contradice: la poetisa no nació en 1951 sino en 1948. Se quitó los años. Y por lo que toca a la tradicional imagen y muy románticamente piadosa de los matrimonios felices y sucesivos de doña Isabel Ramírez, la madre de Sor Juana tanto con el capitán don Pedro Manuel de Asbaje y Vargas Machuca, padre de la poetisa, como con el también capitán don Diego

16. Revista Abside,Vol.: 15 núm. 4, Oct.- Dic. de 1951, pp. 453-489. 
Ruiz Lozano y Centeno, el sabio zamorano está enterado de todos los pormenores de la investigación de Ramírez España sobre la familia de Sor Juana: conoce, por tanto, y cita los documentos que indican el carácter de hija "natural" de la monja pero lo declara "trágico enigma"; aunque agrega, refiriéndose al testamento de doña Isabel, "pero ese testamento, por sí solo, rebosante de fe y piedad, trasluce cómo rendiría sus cuentas libre de aquella culpa, felix culpa que a Sor Juana dió el ser, y en ella tanta gloria a nuestra gente y al mismo Dios".

En contraste con él, la biografía sorjuaniana sigue fuertemente afectada por la hagiografía. No sólo las biografías sorjuanianas de la primera mitad del siglo sino las que se publican ya muy entrada la época post-mendezplancartiana, reproducen, por lo que hace a la familia de la monja, casi intactos los clichés de Calleja quien cataloga de "legítima unión" la relación de la pareja Asbaje-Ramírez. Así, por ejemplo, todavía en 1983, Clara Campoamor, en su Sor Juana Inés de la Cruz, 17 dice: "poco se sabe de los padres de Juana; él murió joven; la viuda contrajo segundas nupcias con el capitán don Diego Ruiz Lozano". Hoy se sabe que doña Isabel no

17. Madrid, Ediciones Júcar, Colección Los poetas Núm. 53, 1983, p. 12. estuvo casada con ninguno de los dos, que vivió en unión libre con ellos y que, probablemente, eran dos aventureros de los que no se sabe más. Empero, la información de que dispone y cita don Alfonso, como es natural, además de la que ofrecen los jesuitas Diego Calleja, el citado biógrafo de la poetisa, y Juan Antonio de Oviedo, el biógrafo de su director espiritual Antonio Núñez de Miranda, se reduce a repetir la información manejada por los arriba mencionados sorjuanistas de la primera mitad de siglo.

Por lo que hace a la calidad de monja que fue Sor Juana, Méndez Plancarte presenta acríticamente, y contra los datos provenientes de ella misma, a una Sor Juana"exacta en el diario coro diurno y nocturno y en sus oficios de contadora y de archivista", "pródiga con los pobres", "solícita con las enfermas", "partícipe de las demás faenas humildes, como cuidar a las niñas y moler chocolate", obediente ante la priora, "y acreedora, por fin, a ese elogio sumo: "la caridad fué su virtud reina... Nadie la oyó jamás quejosa ni impaciente... Jamás se había visto igual perspicacia..., con tan limpísima candidez de buen natural"... En suma, al contrario de lo que la misma monja nos dice en documentos como la "petición causídica" o la carta a Núñez que el editor de las 


\section{ESPIGA}

Obras Completas no conoció, la Sor Juana que Méndez Plancarte nos presenta es toda una santa.

En lo que respecta a la obra literaria, Alfonso Méndez Plancarte da una somera reseña mencionando, sobre todo, los principales escritos de circunstancia. Desde luego, la mejor opinión que el sabio zamorano da de la obra sorjuaniana consta en su edición de las Obras Completas de la monja que Marcel Bataillon tachó de "magistral y definitiva". 18 En cambio, Méndez Plancarte no avanza nada en lo que concierne a la conversión de Sor Juana: prácticamente reproduce el punto de vista de Calleja. Mejor que nadie, después de sus tres tomos de Poetas novohispanos, Méndez Plancarte está preparado para ubicar a Sor Juana en el concierto de la literatura novohispana del siglo XVII contra el parecer del mismísimo Menéndez y Pelayo cuando afirmaba que "en tal atmósfera de pedantería y aberración literaria, tiene su aparición algo de sobrenatural" refiriéndose a Sor Juana. Al respecto, Méndez Plancarte, luego de enumerar una serie de poetas del siglo XVII novohispano, agrega: "y tantos otros nada desdeñables ni mucho menos, no descubrimos ya una Décima Musa en un absurdo "desierto", sino una reina en una

18. Reseña citada por Marié-Cécile BenassyBerling, Op. cit., p. 15.
Corte lírica que la merece y la real$\mathrm{za}^{\prime \prime}$. Y, en efecto, con ese ánimo repasa la prosa, el teatro, los villancicos, el Sueño, los romances, los sonetos y la poesía del amor proclamando a Sor Juana"emperatriz del idioma".

Poco dice el investigador zamorano del lugar que ocupa Sor Juana en la ciencia de su época. Apoyados en el episodio, contado por Calleja, de la discusión de Juana Inés con los sabios de México organizada por el virrey Mancera, han sido muchos los investigadores que han profundizado en las relaciones que nuestra poetisa-monja tuvo con la ciencia de su época. Para muestra, basta el volumen que la Historia de la ciencia en México de Elías Trabulse ${ }^{19}$ dedica al siglo XVII para ver, como lo hace el autor, la relación entre el discurso del Primer sueño y el discurso científico del siglo XVII novohispano.

\section{El hallazgo de nuevos textos}

Después de las Obras Completas, no han faltado gozos a la investigación sorjuaniana que, de una manera $\mathrm{u}$ otra, han incidido en el conocimiento del ambiente sorjuaniano. Antonio Alatorre ha contribuido en especie no sólo con algún soneto no incluido en las Obras Completas, sino con varios artículos publicados,

19. Tomo II, México, CONACYT/FCE, 1984. 
además de varias revistas extranjeras, en la Nueva Revista de Filología Hispánica, como en Vuelta y aún en Proceso. Estos trabajos y documentos inciden directamente en la biografía de Sor Juana por afectar la comprensión que hoy se tiene del hecho sorjuaniano. ${ }^{20}$

El tercer centenario de la muerte de la poetisa, por lo demás, nos ha regalado con varias ediciones facsimilares de los tres tomos que de la obra sorjuaniana se publicaron en el siglo XVII. ${ }^{21}$ En el segundo de los tomos que de la edición facsimilar ha hecho el Frente de Afirmación Hispanista, Guillermo Schmidhuber publica un texto desconocido de Sor Juana que, como tal, enriquece los datos biográficos de la monja. ${ }^{22} \mathrm{El}$

20. A Antonio Alatorre se debe una edición de los Enigmas ofrecidos a la casa del placer, México, El Colegio de México, 1994. En la introducción que precede al texto sorjuaniano hay una buena cantidad de datos biográficos que atañen a la fama de la monja.

21. Importante es, por ejemplo, la edición hecha por el Frente de Afirmación Hispanista que entre 1989 y 1995 publicó los mencionados tres tomos.

22. Op. cit., pp. 529 y ss. Allí no sólo publica Schmidhuber el texto encontrado por él sino que hace una somera contrastación con los documentos análogos ya conocidos como son el 409, y el 412 de las Obras Completas. En realidad, Schmidhuber omite la contrastación más importante, a saber: la contrastación con el texto de profesión de votos, el 411 de las Obras Completas. texto encontrado por Schmidhuber tiene todas las apariencias de ser un formulario o machote usado en los conventos novohispanos para las tan frecuentes ceremonias de renovación de votos: de ello nos convencen tanto los 3 espacios en blanco -después del "yo" inicial, tras la expresión también inicial "monja profesa de este convento" en que debe ir el nombre del convento, y tras la frase final "lo firmé en"-, como el simple hecho de hallarse "reimpreso" en 1731. El documento lleva por título "Protesta de fe y renovación de votos religiosos que hizo y dejó escrita con su sangre la madre Juana Inés de la Cruz monja profesa del convento de San Jerónimo de México". De hecho es ambas cosas además de un sumario testamento. Consta, por tanto, de tres partes: profesión de fe, impetración de perdón y renovación de votos.

En medio de una serie de expresiones-cliché, hay un par de expresiones sorjuanianas como cuando dice: "que tan mal he cumplido y de que me pesa en el alma" $\mathrm{y}^{\text {"cuya }}$ concepción purísima libre de toda mancha de pecado en el primer instante de su ser, hago votos de creer y defender hasta dar la vida". El lector atento de los textos religiosos de la monja sabe muy bien el grado de recurrencia de este tipo 


\section{ESPIGA}

de expresiones en la escritura de la Sor Juana de los noventa. A pesar de ello, no puede soslayarse el peso que haya podido ejercer en ellas la moda. Con todo y eso, esas expresiones de esta índole pueden ser consideradas como una contribución a la biografía de la monja al menos como expresión del prestigio de la monja y la influencia ejercida por ella en el mundo monjil de la ciudad de México ya bien entrado el siglo XVIII.

\section{Los hitos postmendezplancartianos}

El primero de los hitos postmendezplancartianos lo constituye el hallazgo y la publicación de la llamada "Carta de Monterrey" también conocida como la "Carta al P. Núñez" o "Carta de la ruptura" a cargo del humanista jaconense, avecindado en Monterrey, Monseñor Aureliano Tapia Méndez. Ello tuvo lugar en abril de1980 en la biblioteca del Seminario de Monterrey. Desde luego, este es uno de los momentos estelares de la investigación sorjuanista. El documento por él descubierto es una carta hasta entonces desconocida que Sor Juana escribe a su confesor, el jesuita zacatecano Antonio Núñez de Miranda. 23 Se trata de un documento auto-

23. Varias ediciones de este importante documento han sido hechas por el mismo biográfico de la misma índole que la Respuesta a Sor Filotea de la Cruz que explica muy bien las relaciones entre la monja y su confesor, los puntos de vista de Sor Juana sobre su proyecto de vida $\mathrm{y}$, en general, sobre la educación femenina en la Nueva España, además de las circunstancias de una serie de actividades desempeñadas por ella hasta 1682, fecha de la carta. Llama la atención, dentro de los intentos actuales de una biografía de Sor Juana que, salvo Aureliano Tapia Méndez, en la más reciente edición de la carta no se mencione para nada el año de noviciado que transcurre la monja en San Jerónimo antes de profesar y que va de febrero de 1668 a febrero de 1669.

Aureliano Tapia Méndez, Autodefensa espiritual de Sor Juana, Monterrey, UANL, Dirección General de Investigaciones Humanísticas, 1981, 100 págs. Aureliano Tapia Méndez, Carta de Sor Juana Inés de la Cruz a su confesor. Autodefensa espiritual, edición facsimilar, Monterrey, Impresora Monterrey, 1986. Aureliano Tapia Méndez, Carta de Sor Juana Inés de la Cruz a su confesor. Autodefensa expiritual. Estudios y notas de Aureliano Tapia Méndez, Monterrey, Producciones Al Voleo El Troquel, 1993. Octavio Paz lo incluye en la $3^{\text {a }}$ edición de su Sor Juana Inés de la Cruz..., Op. cit.. Yo mismo hice una edición y un pequeño comentario al escrito en mis Estudios sorjuanianos (Morelia, Instituto Michoacano de Cultura, 1988). La edición, sin embargo, más importante, la ha publicado Antonio Alatorre en la NRFH, Tomo XXXV, Núm. 2, 1987, pp. 591-673. 
Por lo demás, el período que va de la Carta de Monterrey hasta el centenario de la muerte de la poetisa, en 1995, está caracterizado por abundantes hallazgos y sus respectivas publicaciones que vinieron a introducir nuevas perspectivas en la investigación sorjuanista: nuevos textos sorjuanianos, datos biográficos desconocidos, intereses nuevos como el que gira en torno a lo que se ha dado en llamar la"conversión de Sor Juana", hipótesis nuevas construidas sobre viejos datos. Me refiero a cosas como la polémica en torno a la Carta Atenagórica que ha recibido nueva documentación en obras como los Enigmas ofrecidos en la casa del placer, publicada por Antonio Alatorre en 199424 y a Serafina y Sor Juana, del mismo Alatorre y Martha Lilia Tenorio, 25 en que lanzan nuevas hipótesis, deshacen atribuciones de textos que por esta época se han multiplicado.

24. México, CONACULTA, 1994

25. México, El Colegio de México, 1998. Véase las publicaciones y atribuciones de Elías Trabulse en torno a la Carta de Serafina de Cristo: Elías Trabulse, El enigma de Serafina de Cristo. Acerca de un manuscrito inédito de Sor Juana Inés de la Cruz, Toluca, Instituto Mexiquense de Cultura, 1995; Elías Trabulse, Los años finales de Sor Juana: una interpretación (1688-1695, México, Centro de Estudios de Historia de México Condumex, 1995
Alatorre y Tenorio han contribuido con su Serafina y Sor Juana no sólo a documentar el epistolario en torno a Sor Juana sino que su obra documenta autorías, atribuciones y contra-atribuciones en torno a la también recientemente publicada Carta de Serafina de Cristo (Edición facsimilar, 1991). Este libro, como decía, lanza nuevas hipótesis sobre la crónica de los últimos cinco años, los de los noventa, en la vida de la monja. Por ejemplo: la Carta atenagórica, que Octavio Paz llama"carta de más", habría tenido su origen en las visitas que el obispo de Puebla, don Manuel Fernández de Santa Cruz, solía hacer a Sor Juana en el locutorio del Convento de San Jerónimo. Según, en cambio, Antonio Alatorre y Martha Lilia Tenorio, si bien es cierto que Fernández de Santa Cruz fue uno de los visitantes al locutorio de Sor Juana, eran muchos los personajes importantes que consultaban a la monja novohispana quien se había convertido en la consultora de México en las más altas cuestiones de la filosofía y teología. La carta estaría dirigida por Sor Juana a uno de estos visitantes ilustres: los autores de Serafina y Sor Juana piensan que tal personaje, el destinatario de la carta, habría sido el teólogo agustino Antonio Gutiérrez o algún otro teólogo. Del escrito se habrían hecho copias, como se acostumbra en esos casos en 


\section{ESPIGA}

ese mundillo; una de esas copias habría llegado a manos del obispo de Puebla, don Manuel Fernández de Santa Cruz quien la habría hecho imprimir, como ya se ha dicho, con ese nombre. En pocas palabras, el libro Serafina y Sor Juana enfatiza la cátedra real que desde el locutorio de su convento sustenta Sor Juana en cuestiones selectas de filosofía y teología, modifica la opinión vulgata sobre estos años en torno al año noventa, y desemboca en la Carta Atenagórica, la "carta de más" de Octavio Paz.

En el referido libro Serafina y Sor Juana, sus autores además modifican la idea que había prevalecido hasta la fecha sobre las dimensiones del terremoto desencadenado por la Carta Atenagórica: no se trató sólo de un sismo nacional en el que participaron algunos teologuillos novo hispanos sino que desencadenó reacciones portuguesas como la Apología a favor do P. Antonio Vieyra publicada en Lisboa en 1727 firmada por Sor Marguerida Ignacia, seudónimo del Dr. Luis Gonçalves Pinheiro, "clérigo do hábito de Sao Pedro".

Obras como Serafina y Sor Juana han puesto de actualidad en la década de los noventa la Carta Atenagórica tras cumplirse los trescientos años de su escritura. Además de lo ya mencionado, recojo aquí Sor Juana
$\mathcal{E}$ Vieira ${ }^{26}$ obra colectiva que estudia los escritos, cartas principalmente, de los últimos cinco años de Sor Juana. Sobre el mismo asunto cito la Sor Juana Inés de la Cruz e o Padre Antonio Vieira ou a disputa sobre as finezas de Cristo, de Joaquín de Montezuma de Carvalho, ${ }^{27}$ en la que recoge una antología de documentos sobre la Carta Atenagórica y los referidos últimos cinco años de Sor Juana. Las circunstancias de escritura de la Carta Atenagórica, en efecto, al ser un documento central en la llamada "conversión" de Sor Juana, han sido replanteadas por Antonio Alatorre sobre todo en el ya mencionado libro Serafina y Sor Juana que escribe con Martha Lilia Tenorio. ${ }^{28}$ Según la opinión comúnmente sustentada la Carta Atenagórica el destinatario de la carta a quien la monja se refiere en las primeras palabras del

26. Edición de K. José Bijuesca / Pablo A. J. Brescia, Anejo de la revista Tinta, Santa Bárbara, California, 1998.

27. México, Frente de Afirmación Hispanista, 1998.

28. México, El Colegio de México, 1998. Véase las publicaciones y atribuciones de Elías Trabulse en torno a la Carta de Serafina de Cristo: Elías Trabulse, El enigma de Serafina de Cristo. Acerca de un manuscrito inédito de Sor Juana Inés de la Cruz, Toluca, Instituto Mexiquense de Cultura, 1995; Elías Trabulse, Los años finales de Sor Juana: una interpretación (1688 - 1695), México, Centro de Estudios de Historia de México Condumex, 1995 
escrito como "Muy señor mío" sería el obispo de Puebla don Manuel Fernández de Santa Cruz. Este importante personaje, habría sido uno de los muchos visitantes del locutorio de San Jerónimo quien luego de admirarse en una ocasión de los altos conceptos vertidos por la monja en un juicio crítico al "Sermón del Mandato" del famoso predicador portugués Antonio Vieira, le pide a Sor Juana que ponga por escrito esos discursos. Ella lo hace, los manda al obispo y, sin que ella estuviera enterada, él los hace publicar con el nombre de Carta Atenagórica que, como diremos adelante, le desata en su contra todos los rayos del Olimpo.

En todo caso, ahora estamos en mejores condiciones de hacer un mejor inventario del estado de cosas más cercano a lo que fue realmente la vida y la obra literaria de Sor Juana Inés de la Cruz y de sus alcances para la cultura latinoamericana. Conocemos mejor, desde luego, no sólo la cultura colonial americana y la novohispana sino el mundo de Sor Juana. Hoy, además, sabemos más de los sistemas textuales colonial y novohispano e, incluso, otras cuestiones como la vida religiosa americana, la bibliografía colonial: Además, hoy podemos disfrutar de notables avances de la exégesis bíblica en cuestiones que fueron determinantes para la mentalidad colonial. Y con respecto a la monja novohispana, tenemos hoy un mucho mejor mirador gracias a un nutrido y entusiasta grupo de sorjuanistas no sólo del mundo hispánico sino del mundo europeo como la investigadora francesa Marié-Cécile Benassy-Berling, con su tesis doctoral Humanismo y religión en Sor Juana Inés de la Cruz. ${ }^{29}$. Nuestro punto de partida se basa en el postulado que comparten Pero Grullo y Octavio Paz en su Sor Juana Inés de la Cruz o las trampas de la fe "hay una relación entre la vida y la obra de un escritor pero esa relación nunca es simple".

Un segundo hito del sorjuanismo de fines del siglo XX lo marcan las publicaciones posteriores a la conmemoración del tercer centenario de la muerte de la monja, en abril de 1995. Esta fecha ha sido el detonador de otro acervo de investigaciones y un alud de publicaciones sorjuanistas de todas clases. Como hemos visto, algunas de las publicaciones, sobre todo las de la segunda y tercera épocas, se han aglutinado en torno a la mencionada Carta Atenagórica, de tal manera que se ha creado un muy movedizo subsuelo que alimenta al cuadro de aprobaciones y des aprobaciones surgidas a raíz de ella y cuyos personajes

29. México, UNAM, 1983. 


\section{ESPICA}

más importantes fueron ya señalados por la misma Sor Juana en su Respuesta a Sor Filotea de la Cruz. Todavía el 2 de septiembre de 2004 Margo Glantz, asidua estudiosa de la poetisa novohispana publicaba un artículo en La Jornada (Sección Cultura, p. $5^{\text {a }}$ ) en donde daba cuenta de la aparición en la colección del Seminario de Cultura Literaria de la UNAM del libro La Carta Atenagórica de Sor Juana: textos inéditos de una polémica, de José Antonio Rodríguez Garrido, un investigador peruano: el libro destruye falsas atribuciones de textos hoy conocidos y de personajes misteriosos del momento y aclara el alcance internacional tanto de la fama de Sor Juana como de la tormenta desatada por la Carta Atenagórica. Ello sólo indica cuánto la poetisa novohispana está viva $\mathrm{y}$ cuánto sus textos suscitan, aún hoy, pasiones.

Con tanto hallazgo como ha estado cargada la época postmendezplancartiana hoy ya no son raras las voces de quienes, como Antonio Alatorre, señalan la urgencia no sólo de unas nuevas Obras Completas sino, como veremos más adelante, ahora sí, una edición crítica. Sin embargo, pese a todos esos caudales el sustrato biográfico de la monja novohispana todavía se estructura, a grandes rasgos, en el referido texto de Calleja. Empero, desde la Juana de Asbaje de Amado Nervo, el 28 de abril de 1910, la primera biografía mexicana de este siglo, hasta la Sor Juana Inés de la Cruz: ¿hagiografía o autobiografía? de Margo Glantz, el más reciente de los acercamientos biográficos a la poetisa, hay ya un gran camino recorrido que, dadas las circunstancias, se antoja largo. Mientras Nervo se alimenta casi exclusivamente de Calleja y, en general, tanto de los datos biográficos que aparecen en las poesías de Fama como de algunos de los poemas de la monja, Margo Glantz puede ya disponer no sólo de la excelente edición de las Obras Completas de la monja a cargo sobre todo de don Alfonso Méndez Plancarte, sino que tuvo a su disposición una serie de descubrimientos, como los mencionados, hechos sobre la vida y la obra sorjuanianas a lo largo del siglo XX, por no mencionar el gran interés suscitado entre los historiadores de lo novohispano no sólo por el siglo XVII sino por la historiografía religiosa. En general, se puede decir que tiene hoy menos validez la denuncia que hace apenas una treintena de años hacía la Historia General de México. ${ }^{30}$ Como muy bien señala Margo Glantz.

30. Cfr. Andrés Lira y Luis Muro,"El siglo de la integración", en Historia General de México, tomo II, México, SEP/El Colegio de México, 1976. 
... las cosas han cambiado: el tradicional desprecio se ha trocado en admiración: no es casual que la proliferación de estudios sobre la monja coincida con la proliferación de estudios sobre la Colonia, incrementados en la década de los setenta e innumerables a partir de la de los ochenta. ${ }^{31}$

La bibliografía que sobre Sor Juana Inés de la Cruz y su obra ha hecho llover el tercer centenario de la muerte de la sabia monja novohispana es mucha: rebasa, pues, este espacio. Sin embargo, he de mencionar, a guisa de ejemplos, un somero muestrario de ella. Empiezo por algunas de las obras que traen la marca de José Pascual Buxó quien en los últimos quince años ha enriquecido los conocimientos que se tenían de la obra de Sor Juana. Me place acordarme aquí de su Sor Juana Inés de la Cruz: amor y conocimiento, 32 o Sor Juana Inés de la Cruz y las vicisitudes de la crítica. ${ }^{33}$ Los vendavales de los trescientos años han traído consigo también alguna que otra biografía, como la Sor Juana Inés de la Cruz de Carmen Saucedo Zarco y la también la Sor Juana Inés de la Cruz de Juan Galaviz, cuya aportación más importante, digá-

31. Op. cit., pp. 22 y s.

32. México, UNAM, 1996.

33. México, UNAM, 1998. moslo cortésmente, es la recomposición que presentan.

\section{Cuentas, cuentos y recuentos}

Frente a la ya citada publicación de obras como las de Paz, cerrada al universo de lo religioso, o como la de Pfandl, basada en prejuicios de escuela agravados por la escasez de datos con que tuvo que trabajar, la investigación en torno a Sor Juana se agudizó tras huellas que habían dejado Henríquez Ureña y Dorothy Schons. Gracias a los trabajos de Antonio Alatorre, de José Pascual Buxó, de Marié-Cécile BenassyBerling y, en general, del sorjuanismo francés; pero sobre todo, gracias a Alfonso Méndez Plancarte, hoy sabemos mucho más de la poética de Sor Juana aunque todavía no contemos con un estudio completo de ella. El Sueño ha sido punto especial del interés de muchos sorjuanistas. Como Aureliano Tapia Méndez demuestra hacerlo en sus publicaciones a propósito de la Carta de Monterrey, el haber llegado a percibir los matices autobiográficos ha sido una pieza importante que ha contribuido no poco a desentrañar el problema de la conversión.

Por otra parte, el alud de publicaciones que, en torno al tercer centenario de la muerte de la poetisa, ha puesto los puntos sobre muchas 


\section{ESPIGA}

íes aún desfiguradas. Empezaría por las tan alabadas Obras completas de la poetisa a cargo de Alfonso Méndez Plancarte. Sin que ello quiera decir que antes no se habían notado los defectos de la obra del sabio zamorano; mencionaría, desde luego, la propuesta que hace Antonio Alatorre de llevar a cabo una edición crítica 34 con el doble argumento de que, en primer lugar, la edición del humanista zamorano si bien "tiene algo de crítica", no es propiamente hablando una edición crítica. "El texto que en ella leemos es, en no pocos pasajes, resultado de un cotejo de varias ediciones antiguas. Méndez Plancarte procuró ofrecer una lectura sin tropiezos y sin lunares, y para ello empleó las técnicas filológicas consagradas, que refuerzan y refinan eso no técnico que es el sentido común." (p. 493) Como parte de la edición facsimilar que en 1995 publicó la UNAM de los tres tomos que contienen la obra sorjuaniana (Inundación castálida (1689), Segundo volumen (1692) y Fama y Obras póstumas (1700), Gabriela Eguía - Lis Ponce publicó un, como dice Alatorre, "cuidadoso registro de las erratas, las mejoras, las alteraciones y omisiones... que en las sucesivas ediciones se fueron introduciendo" que sirve como punto de arranque para la deseada edición crítica de la obra sorjuaniana.

34. "Hacia una edición crítica de Sor Juana", en NRFH, tomo LI, Núm. 2003-2, pp. 493-526.
En el artículo en cuestión, Alatorre da una serie de ejemplos y propone una serie de avances para la tal edición crítica señalando, de paso, lecturas erróneas de la edición de Méndez Plancarte quien no tuvo a la vista las primeras ediciones de Inundación castálida y Segundo volumen. Gracias a la tenacidad y vocación de filólogo, y a su incansable sorjuanismo, el mismo Alatorre ha estado publicando textos que seguramente entrarán en una nueva edición de las Obras Completas de Sor Juana. Me refiero no sólo a composiciones como sonetos, sino a los ya citados Enigmas ofrecidos en la casa del placer, ${ }^{35}$ publicados en $1994,36 \mathrm{y}$ a su incursión, también ya referida, junto a Martha Lilia Tenorio en el publicitado asunto de Serafina.

Sobre el epistolario en torno a Sor Juana escrito en la década de los noventa de ese siglo XVI, Sara Poot Herrera en Los guardaditos de Sor Juana ${ }^{37}$ también hace una serie de incursiones cuyo centro es la polémica autoría de la Carta de Serafina de Cristo. Eso arrojará luz sobre las demás cartas sobre todo la Atenagórica y la Respuesta a Sor Filotea de la Cruz.

35. México, El Colegio de México, 1994.

36. México, CONACULTA, 1994

37. México, UNAM, 1999. 
Dentro de ese mismo sorjuanismo devoto, José Pascual Buxó regresa a la poetisa de sus estudios anteriores a la poética de Sor Juana, como la incursión en 1984 a la poética del Sueño en su libro Las figuraciones del sentido. Ensayos de poética semiótica, 38 con textos como El enamorado de Sor Juana en donde presenta, al editar la Carta laudatoria a la insigne poetisa la señora Soror Inés Juana de la Cruz, 39 la personalidad literaria de Francisco Álvarez de Velazco Zorrilla, el colombiano "enamorado de Sor Juana" autor de unas endechas a su "paisanita querida". Han salido publicados, mientras tanto, una serie de estudios a la vida y obra de Sor Juana que permiten hoy tejer, con mayor puntualidad, los trazos de una poética sorjuaniana. Fredo Arias de la Canal ha incursionado en Las fuentes profanas de "Primero sueño"40 empezando por Sócrates, Platón y Aristóteles y va recogiendo por aquí y por allá las semillas de una tradición que pasando por Góngora y Descartes desemboca en el Sueño de Sor Juana.

Margo Glantz hace lo mismo en su Sor Juana Inés de la Cruz: ¿hagiografía o autobiografía? ${ }^{41}$ Incursiona, ya

38. México, FCE,1984

39. México, UNAM, 1993.

40. México, Frente de Afirmación Hispanista, A. C., 1998.

41. México, Grijalbo / UNAM, 1995. expurgando, ya proponiendo fuentes, tanto en la biografía sorjuaniana, como en la poética de Sor Juana. La misma autora explora, mediante puntuales estudios de sorjuanistas distinguidos, muchas de las más conocidas circunstancias de la vida de la poetisa en la convocatoria que lleva a cabo en la obra colectiva Sor Juana Inés de la Cruz y sus contemporáneos. ${ }^{42} \mathrm{Al}$ ya varias veces mencionado Antonio Alatorre se debe la valiosa reedición de la Juana de Asbaje que Amado Nervo había publicado en 1910 en el contexto del primer centenario de la independencia de México. En su introducción, Alatorre traza un panorama de lo que han sido algunos de los acercamientos a la poética de Sor Juana.

Hoy se percibe con mucha mayor claridad el significado de su gesto final. Por lo pronto, parece que no debe insistirse en una explicación monocausal y que parece mucho más apegado a la realidad pensar en la confluencia de circunstancias y causas variadas, tanto internas como externas. No es sólo la manía de dar limosna del arzobispo don Francisco de Aguiar y Seixas, por ejemplo, lo que la hace desprender-

42. México, UNAM, Facultad de Filosofía y Letras / Centro de Estudios de Historia de México, Condumex, Colección Cátedras, 1998. 


\section{ESPIGA}

se de su biblioteca y demás cosas, aunque desde luego ello tenga que ver, no es sólo el vendabal que se le viene encima por la publicación de la Carta Atenagórica, aunque desde luego incida; como también inciden la Carta de sor Filotea, las hambres del 92, la inminencia de las bodas de plata de profesa, el acercarse del fin de siglo, la llegada de la menopausia, la quiebra de su modelo epistemológico-religioso; el cumplimiento de su ideal de morir bella y joven, como un racimo de modelos femeninos sacados del santoral o como la rosa, "y no ver el ultraje de ser vieja"; la muerte de sus amigos cercanos y parientes. Todo esto junto crea el clima de la conversión y dan tono a la vida de Sor Juana en sus dos últimos años de vida.

El estudio del Sueño también ha sido incluido en las más recientes bibliografías desde distintas ópticas. Con la mirada de un estudioso de la filosofía, Víctor Gerardo Rivas publica en 2001 su libro La sombra fugitiva: la poética del precipicio en el Primero sueño de Sor Juana y la comprensión del humanismo barroco. 43

Por lo general, la biografía de Sor Juana sigue estando plagada de lugares comunes, enormes lagunas y urgentes tareas. No se sabe casi nada de su infancia; su estancia

43. México, UNAM, fac. de Fil. Y Letras, 2001. entre los parientes de la Ciudad de México, antes de pasar al palacio virreynal, aún es un enigma. De la misma estancia en la familia de los Mancera es bien poco lo que se sabe más allá de la anécdota. Si bien se conocen las veinte lecciones de latín que le impartió el Bachiller de Olivas, no ha habido un intento sistemático y completo de establecer cuál fue la ciencia y cuál la autoeducación de Sor Juana. Todavía sigue habiendo vacío con respecto a los cargos que Sor Juana tuvo en el convento. Como señala Méndez Plancarte, el retrato hecho por Miranda en 1713 para el convento de San Jerónimo, menciona su "empleo de Contadora en dicho Convento, tiempo de nueve años". También se menciona su función de archivista del convento. ${ }^{44}$ Consta, sí, a decir de Méndez Plancarte, "en documentos que aún conservan inéditos los señores Salceda y Ramírez España", y siguen sin ser publicados hasta la fecha, "su primer oficio de 'portera segunda' y su nombramiento de 'secretaria'". 45

Todavía es manejado como una especie de secreto, cuyas fuentes documentales no se dan a conocer,

44. Méndez Plancarte cita a González Obregón, op. cit. y a Jesús Flores Aguirre, "Un retrato de Sor Juana, en Papel de Poesía, Saltillo, enero, 1944.

45. Méndez Plancarte no menciona fechas. 
las dos ocasiones, consignadas por Ezequiel A. Chávez, en que"sus compañeras la eligieron, por unanimidad, Abadesa" y que ella rechazó. Aún sigue vigente la queja de Méndez Plancarte de que no sabemos "cúya es su cita entrecomillada, ni de ello conocemos otro vestigio". Aunque hay numerosos indicios de que Sor Juana escribió una buena cantidad de cartas a personajes sobresalientes de su tiempo: hoy casi se ha perdido la esperanza de dar con alguna de ellas, más allá de las que conocemos. Pese a ello, a sus trescientos años de muerta, la Sor Juana a quien hoy rendimos homenaje es una Sor Juana viva, vigente y actual.

Dentro de las exploraciones de la poética sorjuaniana que han tenido lugar en los últimos años, hay que colocar, en primer lugar, los tres primeros tomos de la edición de Alfonso Méndez Plancarte de las Obras completas de Sor Juana aparecidos entre 1951 y 1955. El 8 de febrero de ese año moría don Alfonso. El tercer tomo es una incursión magistral a la poética sorjuaniana que había ensayado no sólo en sus eruditas introducciones sino sobre todo en su sistema de notas de pie de página en donde el sabio zamorano no sólo identifica estrofas y metros, sino que traza en cada caso la tradición que de tal o cual versificación ha desarrollado el siglo de oro español, o el trato que a determinado tema ha dado la literatura grecolatina. En el tercer tomo, además, dedicado a los Autos y loas, analiza puntualmente, composición por composición y verso a verso, los tipos de estrofa que la poetisa emplea: que endechas, liras, décimas, sonetos, romances, ovillejos, pareados. Décimas de pie quebrado, ovillejos ecoicos, romances con estribillos y cosas así.

Martha Lilia Tenorio ha hecho un estudio concienzudo de los villancicos de Sor Juana. ${ }^{46}$ Allí, no sólo ofrece un excelente ensayo sobre el villancico novohispano sino que lleva a cabo un estudio de los esquemas de versificación empleados en esta composición por la monja. Allí muestra, por ejemplo, los distintos tipos de romances que la poetisa despliega en sus villancicos: el romance octosílabo que la monja usa para "las jácaras, las composiciones de corte más convencional o de carácter más narrativo o discursivo, de las introducciones de las ensaladas"; ;7 el romance hexasílabo, el romance heptasílabo, el romance endecasílabo, diferentes combinaciones estróficas romanceadas, estrofas aconsonantadas, estrofas asonantadas y una variedad

46. Los villancicos de Sor Juana, México, El Colegio de México, 1999.

47. pp. 66s. 
grande de combinaciones métricas. También como incursiones a la poética sorjuaniana pueden considerarse las que hace Sara Poot Herrera en su libro Los guardaditos de Sor Juana. ${ }^{48} \mathrm{La}$ autora, que hace reiteradas incursiones a la poética de la Décima Musa, estudia allí, en efecto, además de las cartas, Los empeños de una casa, el asunto de La segunda celestina, los romances de Sor Juana y cosas así, además de ofrecer un panorama de los últimos hallazgos, publicaciones y controversias en torno a Sor Juana.

Lo que aquí echamos de menos es una presentación completa del arte literario expresado en la obra de Sor Juana Inés de la Cruz bajo el supuesto expresado por Paz en su Sor Juana Inés de la Cruz o las trampas de la fe tanto de que hay una relación entre la vida y la obra de un escritor como de que esa relación nunca es simple; de que la vida no explica enteramente la obra ni la obra explica la vida entre otras cosas porque la literatura es un producto social histórico.

\section{BIBLIOGRAF'́A}

Alatorre, Antonio, 1994, Enigmas ofrecidos a la casa del placer, México: El Colegio de México.
Arias de la Canal, Fredo, 1988, Intento de Psicoanálisis de Juana Inés y otros Ensayos sorjuanistas, México: Ed. Frente de afirmación hispanista.

Buxó, José Pascual, 1996, Sor Juana Inés de la Cruz, amor y conocimiento, México: UNAM.

-1998, Sor Juana Inés de la Cruz y las vicisitudes de la crítica, México: UNAM.

Camponmor, Clara, 1983, Sor Juana Inés de la Cruz, Madrid: Ed. Júcar.

De LA Cruz, Sor Juana Inés, 1951-1957, Obras completas, México D. F.: FCE.

Glantz, Margo, 1995, Sor Juana Inés de la Cruz, ¿hagiografía o autobiografía?, México, ed. Grijalbo.

Herrera Z., Tarsicio, 1984, Buena fe y humanismo en Sor Juana, México D.F.: Ed. Porrúa.

PAZ, Octavio, 1983, Sor Juana Inés de la Cruz o las trampas de la fe, México D.F.: Ed. UNAM.

Poot Herrera, Sara, 1993, Y diversa de mi misma entre plumas ando. Homenaje internacional a Sor Juana Inés de la Cruz, México: El Colegio de México.

1999, Los guardaditos de Sor Juana, México: UNAM.

Rivas, Víctor G., 2001, La sombra fugitiva: la poética del precipicio en el primer sueño de Sor Juana y la comprensión del humanismo barroco, México: UNAM.

TAPIA Méndez, Aureliano, 1981, Autodefensa Espiritual de Sor Juana, Monterrey: UANL.

Trabuise, Elías, 1984, Historia de la ciencia de México, Tomo II, México: CONACYT/FCE.

1995, Los años finales de Sor Juana: Una Interpretaciön (1688-1695), México: Centro de Estudios de Historia de México Condumex.

48. México, UNAM, 1999. 